\title{
Illumination promoting biomass production in wastewater treatment for Rubrivivax gelatinosus
}

\author{
Pan Wu, Xiaohan $\mathrm{Xu}^{\dagger}$ \\ College of Architectural Engineering, Weifang University, Weifang, 261061, China
}

\begin{abstract}
In order to improve the reuse degree of Rubrivivax gelatinosus ( $R$. gelatinosus) resource in soybean producing wastewater (SPW) treatment, the impacts of diverse illumination strength on $R$. gelatinosus biomass and organic contaminant abatement were discussed. It was reported that with the best illumination strength $(6,000$ lux), the production $(3,800 \mathrm{mg} / \mathrm{L})$ of biomass was increased by sixty percent of dark group. COD removal and protein removal rate got 85 and $80 \%$. Influence of diverse illumination strength on $R$. gelatinosus growth were divided into three aspects, including illumination limitation (0-5,000 lux), illumination saturation (5,000-7,000 lux), illumination inhibition (8,000 lux or higher). Meanwhile, at 6,000 lux, bacteriochlorophyll and carotenoids contents, ATP production were increased by 200, 200, 43.9\% severally. Appropriate illumination improved ATP production by increasing the generation of bacteriochlorophyll and carotenoids in photosynthesis. Augment of energy production provoked the biomass production and wastewater treatment. Nevertheless, low or high illumination strength was un-advantage for $R$. gelatinosus growth due to the illumination deficiency or restrian. Moreover, 6,000 lux shortened the treatment time from $96 \mathrm{~h}$ to $48 \mathrm{~h}$.
\end{abstract}

Keywords: Biomass production, Illumination strength, Photosynthesis, Rubrivivax gelatinosus, Soybean producing wastewater

\section{Introduction}

Rubrivivax gelatinosus (R. gelatinosus) sewage disposal technique can be used to recycle biomass for useful products in sewage disposal procedure [1]. R. gelatinosus biomass embodies a great deal of biological nutrients and is non-existent poison [2-7]. These show that $R$. gelatinosus sewage disposal technique cannot produce excess sludge and cause no secondary pollution to the environment. At the same time, $R$. gelatinosus biomass can be recovered to produce high-value substances, resulting in additional benefits. Nevertheless, the production of $R$. gelatinosus biomass was relatively low in the actual wastewater disposal setup [8-10]. Chen et al. [10] concluded that the production of $R$. gelatinosus biomass was at $0.5-0.8 \mathrm{~g} / \mathrm{L}$ in wastewater. An impactful tactics to provoke the production of $R$. gelatinosus biomass is extraordinary important. According to microbial biochemical and metabolism analysis, illumination is one of the most important ones in all the environmental elements. It has great impact $R$. gelatinosus photosynthesis, metabolic way, fertility and wastewater treatment $[11,12]$. Kuo et al. [12] found that illumination affected the carotenoid and energy synthesis pathway of photosynthetic bacteria. Tamiaki et al. [13] found illumination affected chlorosomes and light-harvesting system of photosynthetic bacteria. Thus, illumination is extremely important for $R$. gelatinosus biomass and growth.

Up to now, little news is reported about the impact of illumination strength on $R$. gelatinosus biomass cumulation when grow in the actual wastewater, expressly the actual soybean producing wastewater used in this work. Soybean producing wastewater is innocuous, and riches in basis for $R$. gelatinosus growth [14].

As a result, the aim of the present research is to study the influence of diverse illumination strength on biomass cumulation and COD removal rate; to ensure the best illumination supply for $R$. gelatinosus in actual wastewater; to research the mechanism of illumination to the strengthen of biomass cumulation from the aspect of the synthesis of energy. As Fig. 1 showed, the research methodology and the structure of the article were presented. The impacts of diverse illumination strength on organics reduction, biomass production in SPW, and bacteriochlorophyll and carotenoids contents and ATP production in energy were studied.
This is an Open Access article distributed under the terms of the Creative Commons Attribution Non-Commercial License (http://creativecommons.org/licenses/by-nc/3.0/) which permits unrestricted non-commercial use, distribution, and reproduction in any medium, provided the original work is properly cited.

Copyright (C) 2022 Korean Society of Environmental Engineers
Received August 20, 2021 Accepted November 10, 2021

${ }^{\dagger}$ Corresponding author

E-mail: 104595978@qq.com

Tel: +86 15946542599 Fax: 0536-85799186

ORCID: 0000-0003-4382-1004 


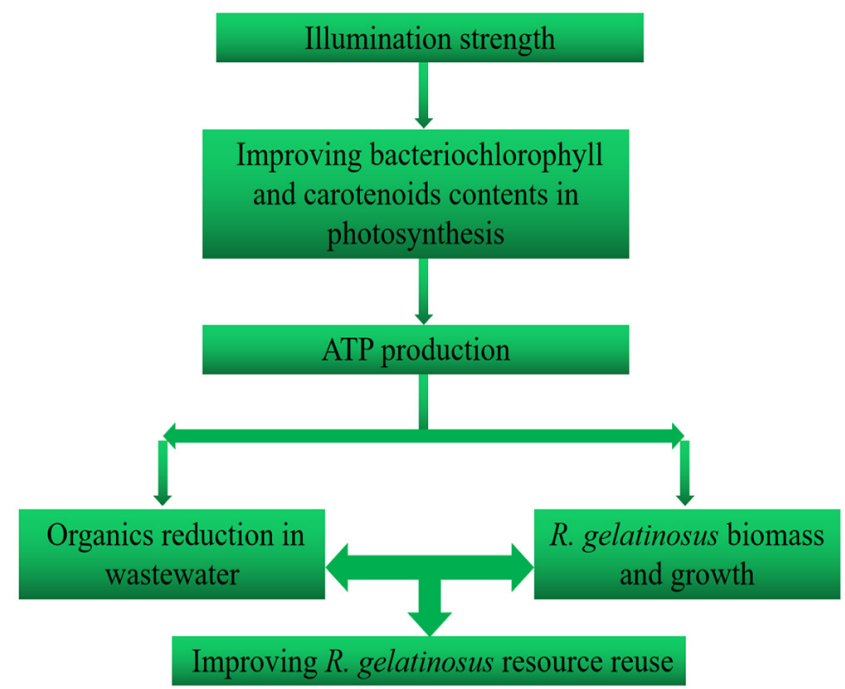

Fig. 1. Flowchart of the research methodology.

\section{Materials and Methods}

\subsection{Materials}

Put logarithmic $R$. gelatinosus at $4^{\circ} \mathrm{C}$ for backup. Initial soybean producing wastewater (SPW) from the plant was thinning through distilled water. The SPW nature appeared at Table 1.

\subsection{Setup of Tests}

A l-L capacity bio-reactor emerged at Fig. 2. In the beginning, $190 \mathrm{mg} / \mathrm{L} R$. gelatinosus and SPW with $600 \mathrm{~mL}$ was filled in bioreactor. At the same time, these conditions $\left(\mathrm{pH} \mathrm{6.9,} 32 \pm 2^{\circ} \mathrm{C}\right.$, $120 \mathrm{rpm}$ ) were provided during $96 \mathrm{~h}$ process.

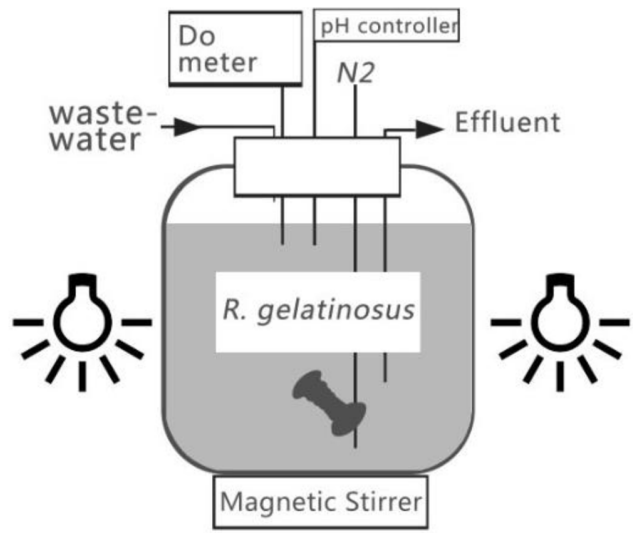

Fig. 2. Bioreactor of $R$. gelatinosus.

\subsection{Control of Illumination Strength}

The illumination-anaerobic condition was used. It was set as bellow: the illumination strength studied were 0 (dark), 2,000, 4,000, 5,000, $6,000,7,000$ and 8,000 lux, and dominated by changing the number of $60 \mathrm{~W}$-illumination bulbs and the distance the bioreactor and the illuminant. The illumination strength was measured by illumination photometer (TES 1330A). Anaerobic was offered by filling the fineness $98.0 \%$ nitrogen gas.

\subsection{Analysis Methods}

The sample was gathered from distinct bioreactors. Centrifugation for sample was performed at 9,000 $\mathrm{g}$ and $4^{\circ} \mathrm{C}$ for $10 \mathrm{~min}$. Protein, COD and protease activity in supernatants (SPW) were detect. COD and dry cell weight were measured in the light of APHA (American Public Health Association). In cell, carotenoids, bacteriochlorophyll contents [15] and ATP production [16] were measured by the HPLC method (Agile 1200, Agile Technologies, Inc), individually.

In the light of China National Food Safety Standard (GB 5009.5-2010) and Kjeldahl, protein content in SPW was measured. Protease activity (PA) in SPW was analyzed at $440 \mathrm{~nm}$ through spectrophotometer (ThermoSpectronic, Rochester, NY) in the light of [17].

\subsection{Statistical Analysis}

SPSS Statistical Software Package was used. Three parallel experiments were set up in each group. Each value was the average \pm error. Differences between 0 lux group and 2,000, 4,000, 5,000, 6,000, 7,000 and 8,000 lux groups were determined by T-test. Clear differences between 5,000, 6,000, 7,000 lux groups were determined by Analysis of Variance.

\section{Results}

\subsection{Impacts of Diverse Illumination Strength on Organics Reduction in Soybean Producing Wastewater}

To observe impact of various illumination strength on soybean producing wastewater (SPW) treatment by $R$. gelatinosus, COD removal (CR), protein removal (PR), protease activity (PA) were examined in all illumination strength. These outcomes were showed in Fig. 3.

As was shown in Fig. 3, contrasting to these of 0 lux, the accommdate of illumination (2,000-8,000 lux) promoted the CR, PR, PA. With 2,000-8,000 lux illumination strength, the CR, PR, PA showed substantially diverse $(P<0.05)$ compared with 0 lux. At the same time, all the highest CR (85\%), PR (80\%) and PA appeared in 6,000 lux. In addition, the CR, PR, PA were alike at 5,000, 6,000 and 7,000 lux (Fig. 3). There was no obvious difference between three groups from each other. Fig. 3 indicated that $R$. gelatinosus secreted more protein degrading enzymes. This accelerated

Table 1. The Water Quality Characteristics of SPW

\begin{tabular}{lccccccc}
\hline Fe & Ca & Mn, Zn, Co, Mg & TN & TP & COD & protein (mg/L) \\
\hline 1 & 127 & 0 & 100 & 60 & 9,000 & 2,000 \\
\hline
\end{tabular}




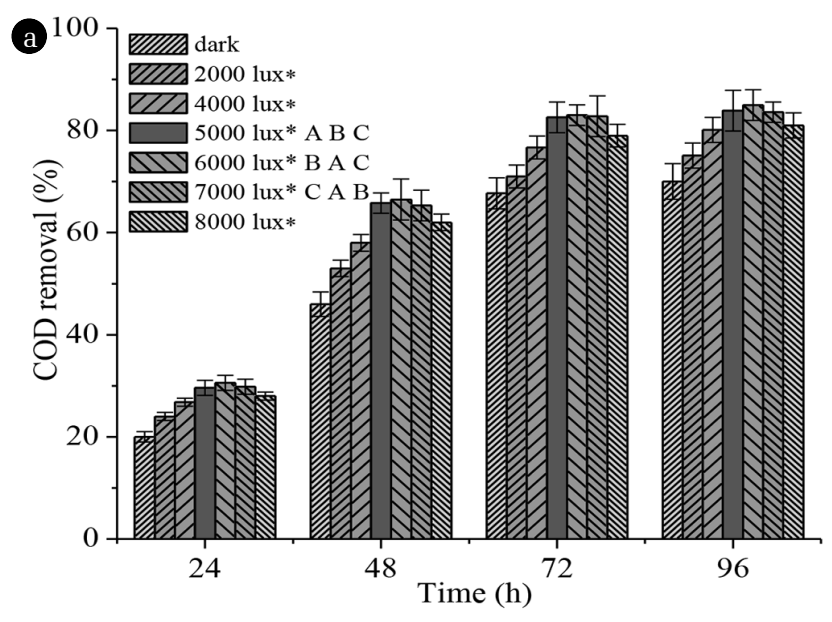

and improved the degradation of organic matter and protein under illumination conditions. Therefore, the CR, PR were improved and the hydraulic retention time was reduced by $48 \mathrm{~h}$ at 6,000 lux. However, the CR, PR did not increase with the increase of illumination strength. At 8,000 lux, the CR, PR began to decline. This might be related to the effect of light on the growth and metabolism of $R$. gelatinosus.

\subsection{Impacts of Diverse Illumination Strength on the Production of $R$. gelatinosus Biomass in SPW}

The impacts of diverse illumination strength on the production of $R$. gelatinosus biomass in SPW were studied. Biomass production (BP) was presented in Fig. 4(a) under all given groups.
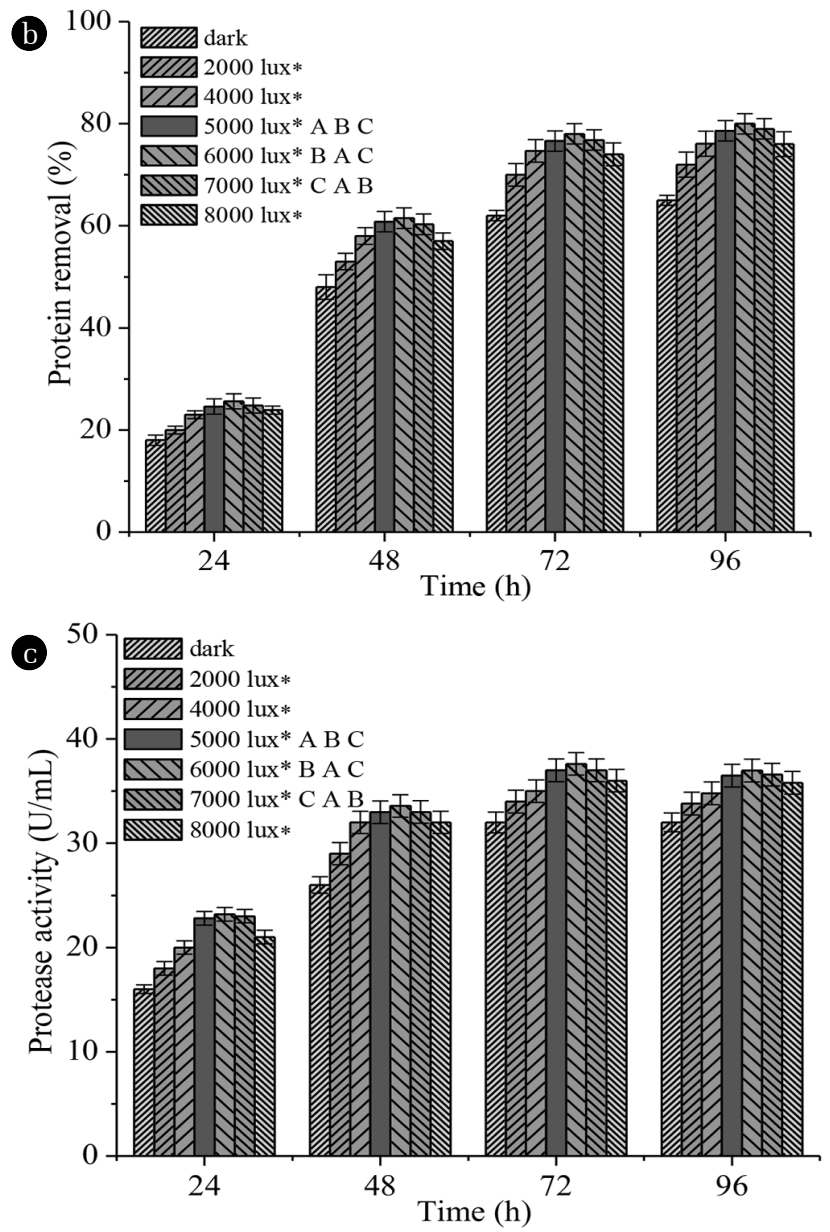

Fig. 3. Diverse illumination strength impacting on COD removal, protein removal and protease activity in $R$. gelatinosus SPW treatment under illumination-anaerobic conditions, (a) COD removal (b) protein removal (c) protease activity. Asterisks express significantly diverse compared to 0 lux. Significant differences between 5,000, 6,000, 7,000 lux groups are depicted by diverse letters ( $A, B$ and $C$ ); thus, groups sharing the same letter are not significantly diverse from each other.
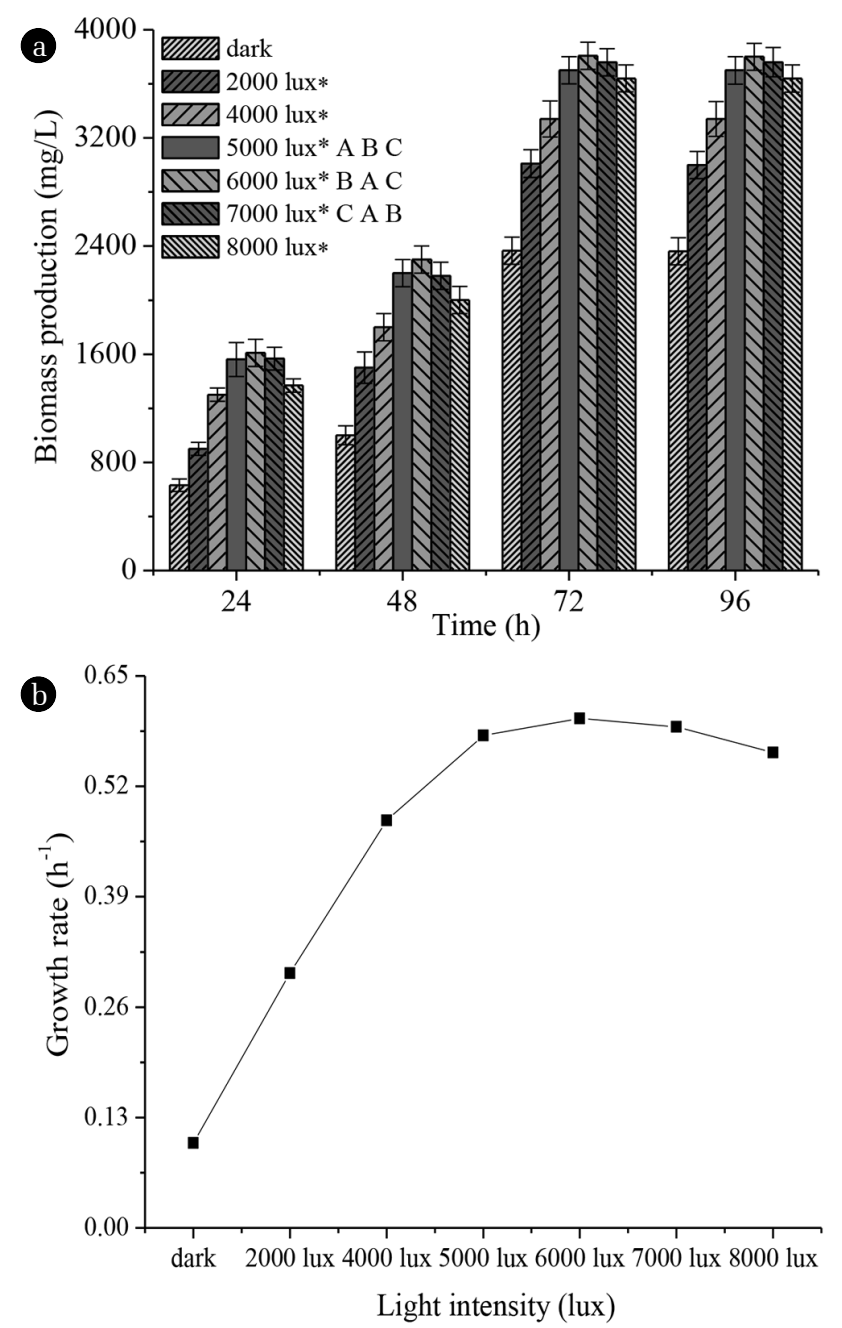

Fig. 4. Impacts of diverse illumination strength on biomass production and the growth rate in $R$. gelatinosus SPW treatment under illumination-anaerobic conditions, (A) biomass production (B) the growth rate. Asterisks express significantly diverse compared to 0 lux. Significant differences between 5000, 6000, 7000 lux groups are depicted by diverse letters ( $A, B$ and $C$ ); thus, groups sharing the same letter are not significantly diverse from each other. 
$R$. gelatinosus could survive in the actual SPW under all given groups without lag phases surveyed. Illumination strength had vital impact on biomass cumulation in $R$. gelatinosus SPW treatment. 2,000-8,000 lux improved the biomass production, and presented obviously diverse $(P<0.05)$, contrasted to 0 lux. At 6,000 lux, $\mathrm{BP}$ got the highest $(3,800 \mathrm{mg} / \mathrm{L})$. Biomass production at 6,000 lux group was 1.6 times of that of dark group (0 lux).

It was noticed from Fig. 3 and Fig. 4(a) that the growth of $R$. gelatinosus, CR, PR and PA increased in the wake of illumination strength from 0 to 5,000 lux. The increase of illumination strength from 5,000 to 7,000 lux did not significantly improve biomass cumulation and COD removal. The increase of illumination strength to 8,000 lux repressed the cumulation of biomass and the removal of COD. To further explain the impacts of diverse illumination strength on the growth of $R$. gelatinosus in SPW, the dependence of specific $R$. gelatinosus cell growth rate on illumination strength was presented in Fig. 4(b).

On the basis of Fig. 4(b), the impact of diverse illumination strength on $R$. gelatinosus growth could be divided to three phases in this work. At illumination limitation (0-5,000 lux), R. gelatinosus growth rate (GR) (see supporting materials) raised along with illumination strength from 0 to 5,000 lux. At illumination saturation (5,000-7,000 lux), GR did not rely on illumination strength. At illumination restrain (8,000 lux or higher), GR declined as the raise of illumination strength. At the same time, the actual work also found that BP, CR, PR, PA were alike at 5,000, 6,000 and 7,000 lux (Fig. 3, Fig. 4). There was no obvious difference between three groups from each other. Different illumination strength had different effects on the $R$. gelatinosus BP and GR in SPW. The main reason was the three illumination stages obtained above. The physiological characteristics of $R$. gelatinosus determined that it needed a certain illumination strength for its growth. However, there were three stages. In the three stages, the effects of illumination on BP, GR were different. At the same time, illumination was necessary for ATP synthesis in photosynthesis. The BP, GR of $R$. gelatinosus and the synthesis of intracellular substances required ATP. The effects of different illumination strength on energy ATP synthesis were also different.

\subsection{Impact of illumination strength on Bacteriochlorophyll and Carotenoids Contents and ATP Production}

Fig. 3 and Fig. 4 presented that the accommodation of illumination (2,000-8,000 lux) increased BP, GR, CR, PR, PA in R. gelatinosus SPW treatment. In addition, when illumination strength was kept at 5,000, 6,000, 7,000 lux, CR and BP were alike and were ultimately showing that 5,000 lux to 7,000 lux was the most suitable illumination strength range for $R$. gelatinosus growth.

According to literature [9], for photosynthetic microorganism, the vital role of illumination is to make in photosynthesis, and then impact productivity. So, the stimulation of illumination in biomass accumulation may be connected with the regulation of photosynthesis. Moreover, illumination acts straight-forward on two photosynthetic apparatuses (bacteriochlorophyll and carotenoids) in photosynthesis. The bacteriochlorophyll and carotenoids plays vital parts in capturing illumination, converting illumination to electron and transferring electron. For clarifying the mechanisms of various illumination strength affecting BP and CR through regulating photosynthesis (PS), changes of bacteriochlorophyll, carotenoids contents were measured under all given groups separately [18-21].

Fig. 5 presented that illumination had vital impact on bacteriochlorophyll and carotenoids contents in $R$. gelatinosus. The bacteriochlorophyll and carotenoids contents got the highest at 6,000 lux, which were 2 times of those of the dark groups. At 5,000, 6,000, 7,000 lux, the bacteriochlorophyll and carotenoids contents were alike. There was no obvious difference between three groups from each other. However, the bacteriochlorophyll and carotenoids contents did not increase with the increase of illumination strength, which was formed with Fig. 3, and Fig. 4. The bacteriochlorophyll and carotenoids contents improved with the increase of illumination strength at 0 to 5,000 lux. The illumination strength at 5,000 lux
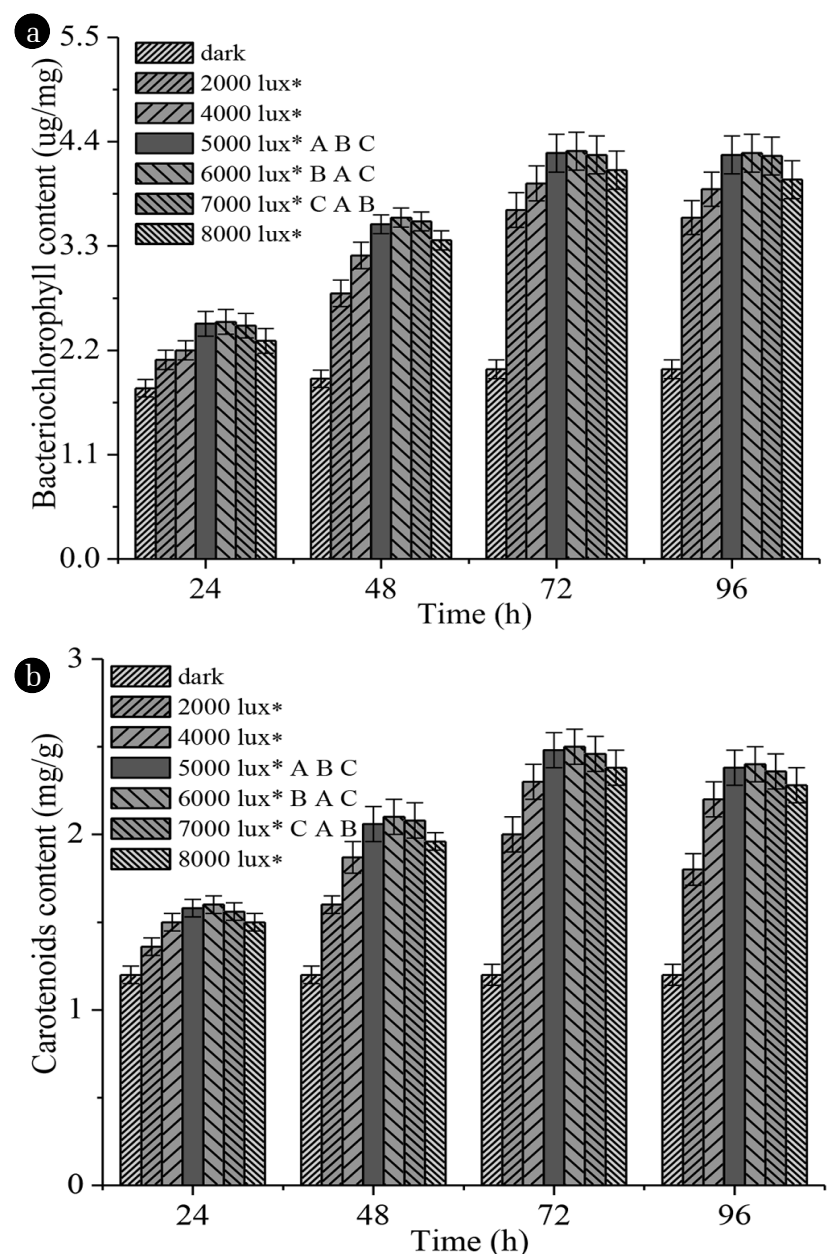

Fig. 5. Impacts of diverse illumination strength on bacteriochlorophyll and carotenoids contents in R. gelatinosus SPW treatment under illumination-anaerobic conditions, (a) bacteriochlorophyll content (b) carotenoids content. Asterisks express significantly diverse compared to 0 lux. Significant differences between 5,000, 6,000, 7,000 lux groups are depicted by diverse letters ( $A, B$ and $C$ ); thus, groups sharing the same letter are not significantly diverse from each other. 


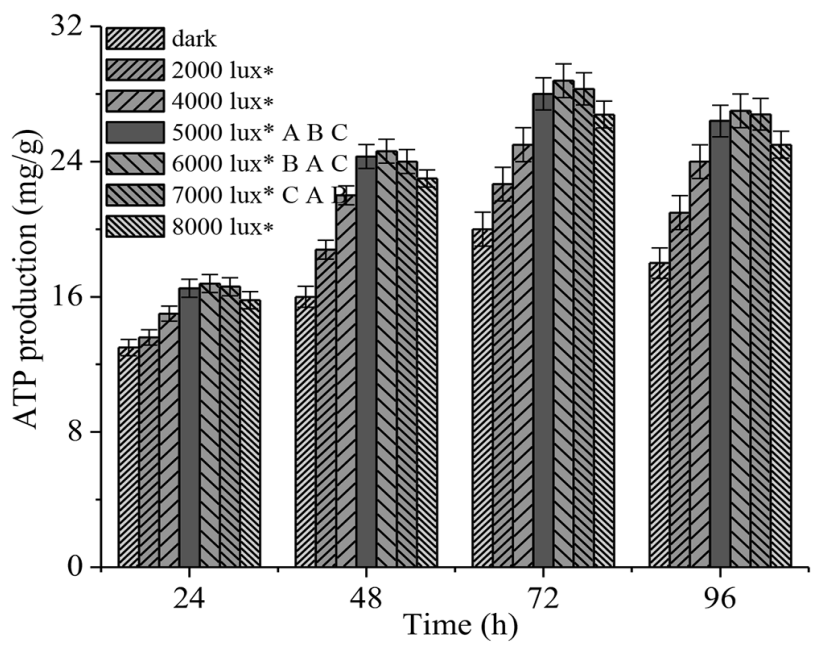

Fig. 6. Impacts of diverse illumination strength on ATP production in $R$. gelatinosus SPW treatment under illumination-anaerobic conditions. Asterisks express significantly diverse compared to 0 lux. Significant differences between 5000, 6000, 7000 lux groups are depicted by diverse letters $(A, B$ and $C)$; thus, groups sharing the same letter are not significantly diverse from each other.

to 7,000 lux did not significantly promote bacteriochlorophyll and carotenoids contents. High illumination strength (8,000 lux) repressed the bacteriochlorophyll and carotenoids contents.

The magnitude of bacteriochlorophyll and carotenoids contents determined the amounts of energy produced by $R$. gelatinosus. ATP production (AP) was measured under all given groups. As presented in Fig. 6, the data were consistent with results in Fig. 3-5. At 6,000 lux, AP was the highest, and was increased by $43.9 \%$ contrasted to the dark group. These indicated that illumination regulated AP by affecting bacteriochlorophyll and carotenoids contents. The increase of AP promoted the CR, PR, BP, GR.

\section{Discussion}

\subsection{Illumination Promoting the Growth of $R$. gelatinosus by Raising AP}

Usually, both the synthesis of intracellular substance in SPW will spend the massive ATP for $R$. gelatinosus. As Fig. 4-6 presented, the supply of illumination (2,000-8,000 lux) improved ATP metabolic rate through regulating two photosynthetic apparatuses contents (bacteriochlorophyll and carotenoids) in photosynthesis. As increase of $\mathrm{AP}$, the $\mathrm{BP}$ and $R$. gelatinosus $\mathrm{GR}$ were raised contrasted to these of 0 lux group.

Meanwhile, the impacts of diverse illumination strength on $R$. gelatinosus growth were divided to three parts on the basis of Fig. 4(b), including illumination limitation (0-5,000 lux), illumination saturation (5,000-7,000 lux) and illumination restrain $(8,000$ lux or higher). To the best of our knowledge no studies have been conducted to observe the impact of illumination strength on the $\mathrm{BP}$ and GR of $R$. gelatinosus cultivated in SPW. But, similar trend was surveyed in past researches. Shi and Yu [22] showed that an increase in illumination strength from 2,000 to 4,000 lux resulted in a sizeable increase in Rhodopseudomonas capsulata growth. However, a substantial decrease in cell growth was surveyed when the illumination strength exceeded 5,000 lux. Zhang et al. [23] found the optimum illumination strength for photosynthetic bacteria (PSB) was $3.1 \mathrm{~W} / \mathrm{m}^{2}$. When the illumination strength was $4.15 \mathrm{~W} / \mathrm{m}^{2}$, PSB biomass decreased obviously. Meanwhile, previous studies also found that supply of illumination improved the effect of wastewater treatment. Lu et al. [24] promoted purple non-sulfur bacteria wastewater treatment by flashing light. $\mathrm{Xu}$ et al. [25] found new insights in light-assisting microbial to treat wastewater.

But, there was difference for the proper illumination strength range between the past researches and the present work. The illumination strength of 2,000 to 4,000 lux was appropriate in past researches [12, 22]. In addition, the cell growth decreased obviously at 5,000 lux or higher [22]. In present work, Fig. 3 and Fig. 4 represented that under 5,000 to 7,000 lux, BP and CR were the highest. In past researches [22, 23], PSB was developed in medium or artificial wastewater. The actual organic wastewater (SPW) was used as basement for $R$. gelatinosus growth in this study. Comparing to the medium or artificial wastewater, the SPW contained massive poor illumination transmission organics (such as protein). Higher illumination strength was needed for $R$. gelatinosus growth in SPW. In addition, different microorganisms and different types of wastewater required different illumination strength ranges.

\subsection{Increase of AP Promoting Degradation of SPW}

Abundant ATP was required for the degradation or absorption of pollutants by $R$. gelatinosus in SPW. During protease synthesis, the polymerization of amino acids and the synthesis of single peptide and polypeptide all consumed extensive ATP [9]. The transport and secretion of enzymes also required a lot of ATP [9]. Moreover, the degraded pollutants in SPW were absorbed into cell by $R$. gelatinosus. This process also needed ATP. Therefore, increase of intracellular ATP had great influence on PA, CR, PR, BP.

Fig. 3(c), 6 showed when AP increased, PA was raised contrasted to 0 lux group under the supply of illumination. In addition, under 2,000-8,000 lux, PA was higher at $72 \mathrm{~h}$ than 0 lux group at 96 h. Increase of ATP sped up protease synthesis by $R$. gelatinosus. Then, degradation of pollutant in SPW was also accelerated. Therefore, both CR and PR in the optimum 6,000 lux group at $48 \mathrm{~h}$ were near to 0 lux group at $96 \mathrm{~h}$ (Fig. 3(a), (b)). In comparison with the darkness (0 lux), to reach the same CR and PR, the supply of illumination (the optimum 6,000 lux) shortened dramatically the treatment time from $96 \mathrm{~h}$ to $48 \mathrm{~h}$. In the whole process, the supply of illumination first increased AP (Fig. 1). After, ATP participated in the whole process of assembly, synthesis, transportation and secretion of protein degrading enzymes. Therefore, proteins and organics in SPW were decomposed into a large number of small molecular substances. At the same time, ATP also participated in the whole process of cell absorption, transport and utilization of small molecular substances. Therefore, the CR, PR, BP, GR in wastewater were increased. Under illumination, the rate and amount of ATP synthesis were greatly increased. The synthesis rate and quantity of protein degrading enzymes were also improved. 
Therefore, at 6,000 lux, the CR and PR rates were increased and treatment time shortened by $48 \mathrm{~h}$. From engineering perspective, the supply of illumination enhanced the productivity of SPW treatment by $R$. gelatinosus and decreased the running cost and consumption of energy.

\subsection{The Mechanisms of Diverse Illumination Strength Regulating the Bacteriochlorophyll and Carotenoids Contents}

Illumination enhanced AP to affect BP, PR and CR by up-adjusting the bacteriochlorophyll, carotenoids contents on photosynthesis. But, Figs. 3-6 indicated that the bacteriochlorophyll and carotenoids contents, AP, BP, CR did not improve with the increase of illumination intensity. Moreover, when illumination strength was controlled at 5,000-7,000 lux, the bacteriochlorophyll and carotenoids contents, ATP production (AP), biomass production $(\mathrm{BP})$, protease activity (PA), COD removal (CR) and protein removal (PR) were the best (Figs. 3-6). The reason was that there was an optimum illumination strength range for $R$. gelatinosus.

On the basis of Figs. 3-6, current work put forward that the optimum illumination strength range was at 5,000-7,000 lux, namely illumination saturation phase (5,000-7,000 lux). Under high illumination strength (exceed 7,000 lux) or low illumination strength (below 5,000 lux), the bacteriochlorophyll and carotenoids contents and AP were low. Then, $R$. gelatinosus could not successfully grow in wastewater. This revealed that different illumination strength had the different mechanisms of affecting the growth of $R$. gelatinosus through regulating the bacteriochlorophyll and carotenoids contents.

When illumination strength was below the optimum range $(5,000$ $-7,000$ lux), $R$. gelatinosus growth was at illumination limitation. In this phase, BP raised with increased of illumination strength (0-5,000 lux) (Fig. 4(a)). This is because illumination induces, regulates and participates in the generation of bacteriochlorophyll and carotenoids. Illumination strength determines the amount of bacteriochlorophyll and carotenoids contents, and then affect ATP production, $R$. gelatinosus growth and COD removal. In this phase, illumination was not adequate. Illumination strength could not maintain the sufficient activity or content of photosynthetic units (bacteriochlorophyll and carotenoids) (Fig. 5) and the sufficient supply of energy. $R$. gelatinosus could not well grow although biomass cumulation was encouraged.

When illumination strength was at the optimum range $(5,000-$ 7,000 lux), the growth of $R$. gelatinosus was at illumination saturation. In this phase, $R$. gelatinosus growth was independent with illumination intensity. Each illumination strength (5000, 6000, 7000 lux) was sufficient for $R$. gelatinosus growth. In this phase, the activity or content of photosynthetic apparatuses (such as bacteriochlorophyll and carotenoids) reached the biggest (Fig. 5). The maximal metabolic activity of $R$. gelatinosus was performed. Bacteriochlorophyll and carotenoids contents, ATP production, biomass production, COD removal were similar (Figs. 3-5), and all reached the best values.

When illumination strength exceeded the optimum range $(5,000$ $-7,000$ lux), $R$. gelatinosus growth was at illumination inhibition. In this phase, BP declined with the increased of illumination strength $(8,000$ lux). In this phase, $R$. gelatinosus growth in SPW was inhibited due to too high illumination intensity. Past other studies also observed photo-inhibition phenomenon [22, 23]. This was because too high illumination strength suppressed the expression of photosynthesis gene about bacteriochlorophyll and carotenoids, and damaged directly the structural of photosynthetic apparatus (bacteriochlorophyll and carotenoids) [11, 12]. As shown in Fig. 5(a) and (b), bacteriochlorophyll and carotenoids contents decreased with the increase of illumination strength in this phase. Then, the ATP production, biomass and COD removal also declined at 8,000 lux, but still were higher than the dark condition since the promoting effect of illumination was bigger than the inhibition.

The supply of illumination was a very effective method. It promoted $R$. gelatinosus wastewater treatment effect and improved $\mathrm{BP}, \mathrm{GR}$. It improved the $R$. gelatinosus resource reuse in wastewater treatment and reduced the secondary pollution of excess sludge to the environment. However, this method had the additional process of illumination supply, which increased the cost. At the same time, this method could not be applied on a large scale. In the future research, we will use solar cell energy-saving illumination source to carry out large-scale application research.

\section{Conclusions}

It was feasible to use illumination to improve wastewater treatment effect and $R$. gelatinosus resource reuse. At 6,000 lux, the production $(3,800 \mathrm{mg} / \mathrm{L})$ of biomass was improved by $60 \%$. COD removal and protein removal rate were enhanced by $10 \%$. Appropriate illumination improved ATP production by increasing the generation of bacteriochlorophyll and carotenoids in photosynthesis. Diverse illumination strength had diverse affecting mechanisms on cell production. Low or high illumination strength were un-advantage for $R$. gelatinosus growth due to the illumination deficiency or restrian. Illumination enhanced the productivity of SPW treatment by $R$. gelatinosus, BP, and decreased the running cost and consumption of energy. These are conducive to the resource reuse of $R$. gelatinosus and wastewater, reduce the secondary pollution to the environment, and produce high value-added nutrients at the same time.

\section{Acknowledgments}

The authors gratefully acknowledge the Setup Science Foundation.

\section{Author Contributions}

X.X. (Professor), director of the research project and author of the research lines. P.W. (Ph.D. student) wrote and revised the manuscript, experimental trials.

\section{References}

1. Zhi R, Cao KF, Zhang GM, Zhu J, Xian G. Zero excess sludge wastewater treatment with value-added substances recovery 
using photosynthetic bacteria. J. Clean. Prod. 2020;250:119581.

2. Cao KF, Zhi R, Zhang GM. Photosynthetic bacteria wastewater treatment with the production of value-added products: A review. Bioresour. Technol. 2020;299:122648.

3. Dong XL, Zhou JT, Liu Y. Peptone-induced biodecolorization of reactive brilliant blue (KN-R) by Rhodocyclus gelatinosus XL-1. Proc. Biochem. 2003;39:89-94.

4. Zilles J, Peccia J, Kim MW, Hung CH, Noguera DR. Involvement of Rhodocyclus-related organisms in phosphorus removal in full-scale sewage treatment plants. Appl. Environ. Microbiol. 2000;68:2763-2769.

5. Li XX, Xu K, Fu WC, et al. Simultaneous in-situ excess sludge reduction and removal of organic carbon and nitrogen by a pilot-scale continuous aerobic-anaerobic coupled (CAAC) process for deeply treatment of soybean sewage. Biochem. Eng. J. 2014;85:30-37.

6. Ponsano EHG, Paulino CZ, Pinto MF. Phototrophic growth of Rubrivivax gelatinosus in poultry slaughterhouse sewage. Bioresour. Tech. 2008;993:836-3842.

7. Mujahid MD, Sasikala CH, Ramana CHV. Production of indole-3-acetic acid and related indole derivatives from L-tryptophan by Rubrivivax benzoatilyticus JA2. Appl. Microbiol. Biotech. 2011;89:1001-1008.

8. Cabello J, Morales M, Revah S. Dynamic photosynthetic response of the microalga Scenedesmus obtusiusculus to light intensity perturbations. Chem. Eng. J. 2014;252:104-111.

9. Kobayashi M and Tchan YT. Treatment of industrial waste solutions and production of useful by-products using a photosynthetic bacterial method. Water Res. 1973;7:1219-1224.

10. Chen JQ, Wei JJ, Ma C, et al. Photosynthetic bacteria-based technology is a potential alternative to meet sustainable wastewater treatment requirement. Environ. Int. 2020;137:105417.

11. Ogbonna JC, Tanaka H. Light requirement and photosynthetic cell cultivation-Development of processes for efficient light utilization in photobioreactors. J. Appl. Phycol. 2000;78:1220712218.

12. Kuo FS, Chien YH, Chen CJ. Effects of light sources on growth and carotenoid content of photosynthetic bacteria Rhodopseudomonas palustris. Bioresour. Technol. 2012;113: 315-318.

13. Tamiaki H, Tateishi S, Nakabayashi S, Shibata Y, Itoh S. Linearly polarized light absorption spectra of chlorosomes, light-harvesting antennas of photosynthetic green sulfur bacteria. Chem.
Phy. Let. 2010;484:333-337.

14. Yu HQ, Wilson F, Tay J. Kinetic analysis of an anaerobic filter treating soybean sewage. Water Res. 1998;32:3341-3352.

15. Edelenbos M, Christensen LP, Grevsen K. HPLC degroupination of chlorophyll and carotenoid pigments in processed green pea cultivars (Pisum sativum L). J. Agric. Food. Chem. 2001;49: 4768-4774.

16. Vectian-Bogues MT, Liquidizer-Pu ML, Vidal-Car MCO. Degroupination of ATP related compounds in fresh and canned tuna fish by HPLC. Food. Chem. 1997;59;467-472.

17. Gessessea A, Dueholmb T, Petersena SB, Nielsenb PH. Lipase and protease extraction from activated sludge. Water Res. 2003;37:3652-3657

18. Coppola G, Gaudio MT, Lopresto CG, Calabro V, Curcio S, Chakraborty S. Bioplastic from renewable biomass: a facile solution for a greener environment. Earth Sys. Environ. 2021;5:231-251

19. Buaisha M, Balku S, Yaman EZ. Heavy metal removal investigation in conventional activated sludge systems. Civil. Eng. J. 2020;6(3):470-477.

20. Mirra R, Ribarov C, Valchev D, Ribarova I. Towards energy efficient onsite wastewater treatment. Civil. Eng. J. 2020;6(7): 1218-1226.

21. Scharnberg ARA, Loreto ACD, Alves AK. Optical and structural characterization of $\mathrm{Bi} 2 \mathrm{FexNbO} 7$ nanoparticles for environmental applications. Emerg. Sci. J. 2020;4(1):11-17.

22. Shi XY, Yu HQ. Response surface analysis on the effect of cell concentration and light intensity hydrogen production by Rhodopseudomonas capsulata. Proc. Biochem. 2005;40:24752481.

23. Zhang C, Zhang H, Zhang ZP, Jiao YZ, Zhang QG. Effects of mass transfer and light intensity substrate biological degradation by immobilized photosynthetic bacteria within an annular fiber-illuminating biofilm reactor. J. Photochem. Photobiol. B. 2014;131:113-119.

24. Lu HF, Zhang GM, Wang CJ, Han T, Zhao RH, Zhu D. Flashing light alleviates photoinhibition and promotes biomass concentration in purple non-sulfur bacteria wastewater treatment. Bioresour. Technol. 2022;343:126107.

25. Xu ZC, Chen SY, Guo SY, et al. New insights in light-assisted microbial fuel cells for wastewater treatment and power generation: A win-win cooperation. J. Power Sources 2021;501: 230000 . 